\title{
Co-relation of functional mobility with anxiety in traumatic below knee amputees
}

\author{
Lavanya R Ayyer ${ }^{* 1}$, Asmita C Moharkar ${ }^{2}$. \\ ${ }^{* 1}$ Assistant Professor, LSFPEF College Of Physiotherapy, Nigdi, Pune, India. \\ ${ }^{2}$ Associate Professor \& HOD of Electrotherapy Department, P.E.S. Modern College Of Physio- \\ therapy, Shivaji Nagar, Pune, India.
}

\section{ABSTRACT}

Background: Amputation is defined as the surgical removal of one or more parts of the body. It causes great stress to the physical and mental wellbeing of an individual. The incidence of lower limb amputation is greater as compared to upper limb amputation. Also lower limb amputees experience more restricted mobility than upper limb amputee patients. Rehabilitation is an important to the recovery of an amputee. In cases of planned amputation, rehabilitation starts before the surgery. It involves physiotherapy, occupational therapy and recreational training. There is little to no studies on the co-relation of anxiety with functional mobility in amputees. This study focusses on the same.

Context and purpose: Amputation causes restricted mobility and decreased quality of life. A study on the relation between anxiety and mobility will indicate a different outlook of a holistic approach while treating mobility issues in below knee amputees.

Materials and methods: This is a one group co-relational study design. Study was conducted after taking approval from the institutional ethics committee and all the subjects gave their written informed consent. The study was conducted at Yashwantrao Chavan Memorial Hospital, Pune.

Result: Statistical analysis of the data was done using the Pearson's co-relation co-efficient and a co-relation was found between anxiety and functional mobility in below knee amputee patients.

Conclusion: There is a co-relation between functional mobility and anxiety. Patients with anxiety showed a reduced performance on the functional mobility scale than the patients without anxiety.

KEY WORDS: Amputation, Anxiety, below knee amputation, functional mobility, rehabilitation.

Address for correspondence: Dr. Lavanya R Ayyer (PT), Assistant Professor, LSFPEF College Of Physiotherapy, Nigdi, Pune -411044, India. E-Mail: lavanya.ayyer@gmail.com

Access this Article online

\section{Quick Response code}

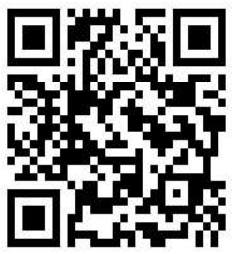

DOI: $10.16965 /$ ijpr.2021.176

\section{Journal Information}

International Journal of Physiotherapy and Research ISSN (E) 2321-1822 | ISSN (P) 2321-8975 https://www.ijmhr.org/ijpr.html DOI-Prefix: https://dx.doi.org/10.16965/ijpr

\section{Article Information}

Received: 03 Aug 2021

Peer Review: 03 Aug 2021

Revised: None
Accepted: 01 Sep 2021

Published (O): 11 Oct 2021

Published (P): 11 Oct 2021

\section{BACKGROUND}

Amputation is defined as the surgical removal of one or more parts of the body. It is known that traumatic amputation can cause a liability on the families and society and a burden on the medical facilities. Depending on the cause of amputation, it is done either as a planned or an emergency surgery. As a planned surgical measure, it is used to control pain or a disease process in the affected limb, such as malignancy or gangrene [1]. Emergency amputations are mostly done in cases of trauma. According to the National Sample Survey of India (NSSI) done in 2012, about 10.66 million people had a locomotor disability. Of them, about 8 million people lived in rural areas and 2.66 million people lived in urban areas. Locomotor disability can be due to many reasons like paralysis, deformity or loss 
of limb. About 93 males per 1000 males and 50 females per 1000 females in both rural and urban areas suffered a disability due to loss of limb [2]. According to a study done in Kolkata in 2013.

\section{The main causes of amputation are:}

1. Trauma - Mainly RTA. (70.3\%)

\section{Peripheral Vascular disease (27.7\%) [3]}

Irrespective of the cause of amputation, it brings a significant and drastic change in a person's life. He goes through many phases to accept the loss of a limb from a state of shock to acknowledgement to finally adjustment [4]. Adjustment involves accepting the change and making the necessary changes in life by training and modifications. The incidence of lower limb amputation is greater as compared to upper limb amputation [5]. Also, lower limb amputees experience more changes in their life after amputation [6].

Disability is a complex phenomenon, reflecting an interaction between features of a person's body and features of the society in which he or she lives. [7] The activity level of an individual and the participation of the individual in the society is affected due to limitations in body structure and function caused by amputation [8]. Mobility following amputation has a direct impact on quality of life. Additionally, personal and environmental factors play an important role in determining outcomes after amputation and also long term functioning of amputees $[8,9]$.

The health-related quality of life (HRQoL) is defined as "an individual's or group's perceived physical and mental health over time. [10] The concept of HRQoL and its determinants encompass those aspects of overall quality of life that can be clearly shown to affect health-either physical or mental [10-13].

- On the individual level, HRQoL includes physical and mental health perceptions (e.g., energy level, mood) and their correlates-including health risks and conditions, functional status, social support, and socioeconomic status.

- On the community level, $\mathrm{HRQOL}$ includes community-level resources, conditions, policies, and practices that influence a population's health perceptions and functional status.
Saarni, Harri Sintonen and Sami Pirkola (2007) conducted a study on the HRQoL decrement and loss of quality adjusted life years associated with pure and comorbid forms of depressive and anxiety disorders and found out that chronic anxiety disoders are associated with poorer HRQoL [14].

\section{The complications associated with amputa- tion are as follows:}

1. Phantom limb pain (50-80\%)

2. Psychological impact involves negative thoughts like depression, anxiety, grief, denial and suicidal tendencies.

High prevalence of anxiety is seen in post-traumatic amputees [15]. Based on the previous studies we can say that the quality of life of an individual who has undergone amputation can be affected due to the presence of anxiety. Understanding the influence of anxiety on the functional mobility of an amputee might be helpful in designing a rehabilitation programme using a holistic approach for a better and faster outcome thereby improving the health-related quality of life. Hence this research is aimed at finding the co-relation between anxiety and functional mobility in traumatic below knee amputee patients.

\section{MATERIALS AND METHODS}

This is a one group co-relational study design. Study was conducted after taking approval from the institutional ethics committee and all the subjects gave their written informed consent. The study was conducted at Yashwantrao Chavan Memorial Hospital, Pune. 30 male traumatic unilateral below knee amputee patients with a post-operative period between 6 months to 2 years were selected using convenient sampling. The age group was kept limited to $30-45$ years as according to the NSSI report, the maximum amputations occur in this age group [2]. Any subjects with an existing medically diagnosed psychological condition, diagnosed musculoskeletal condition of the other leg, deformity or lower limb prosthesis were excluded from the study to maintain the homogeneity of the study so that the results are not biased.

Each subject was assessed for functional mobility using the amputee mobility predictor (AMP) and anxiety was assessed using the Hospital 
anxiety and depression scale (HADS).

Amputee Mobility Predictor Scale (AMP): The AMP is a quick and easily administered tool to assess an amputee's current functional status with or without a prosthesis. It takes less than 10-15 minutes to administer and requires minimal equipment. This scale has 2 parts -Amputee Mobility Predictor without a prosthesis (AMPnoPRO) and with a prosthesis (AMPPRO). For this study the AMPnoPRO was used. The inter-rater reliability for AMPnoPRO is 0.99. The test-retest intrarater reliability is 0.97 . It is one of the first clinically feasible, reliable and valid instrument available for objectively measuring the function in amputee patients [16].

Hospital Anxiety and Depression Scale (HADS): HADS is an objective measure for assessing the caseness of anxiety disorders and depression in an individual. It is a valid and reliable scale for assessing anxiety and depression in medical patients. The HADS has two subscales - the anxiety subscale (HADS-A) and the depression subscale (HADS-D). The anxiety part of this scale has questions with a total score of 21. A score of more than 8 suggests anxiety. Its reliability is $0.68-0.93$. It is found to perform well in assessing the symptom severity of anxiety disorders and depression in somatic, psychiatric, primary care patients as well as in the general population [17].

\section{RESULTS}

The collected data was analysed using the INSTAT version 3. Demographic distribution of the data was done and it was found that maximum number of patients were in the age group of 35-39 years $(n=14)$, followed by $40-44$ years $(n=10)$ and finally 30-34 years $(n=6)$. Further, after implementation of the HADS-A, the patients were divided into two groups, one with anxiety $(n=15)$ and one without anxiety $(n=15)$. For correlating the scores of the AMP with HADS-A, Pearson's co-relation co-efficient was used. The confidence interval was set at $95 \%$ and any value $<0.05$ was considered as significant and $>0.05$ was considered as not significant. The co-relation of functional mobility with anxiety in traumatic below knee amputees is shown in graph 1. As we can see from the graph, the co-relation co-efficient $(r)=-0.09064$. $P$ value is $<0.0001$ which is considered extremely significant.

Pearson's co-relation co-efficient showed significant negative co-relation between the scores of AMP and HADS-A.

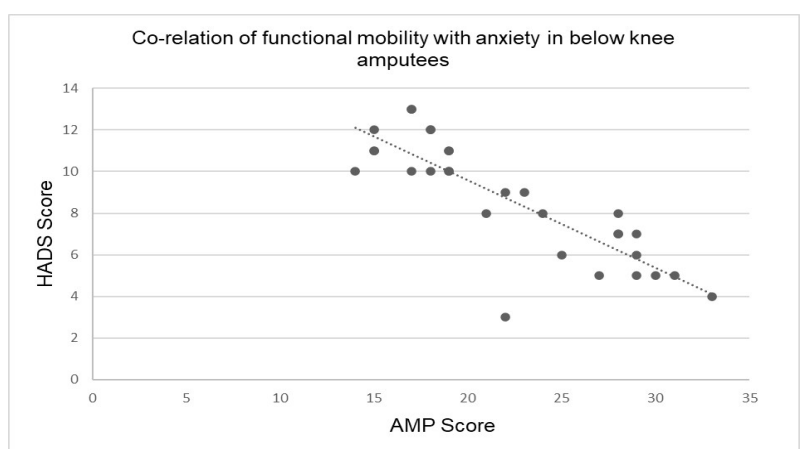

Graph 1: Co-relation of functional mobility with anxiety in below knee amputees.

\section{DISCUSSION}

This study was done to find the co-relation of functional mobility with anxiety in below knee amputees. A total of 30 subjects with below knee amputation satisfying the inclusion criteria were selected for the study. Maximum no. of subjects were found in the age group of 35-39 years. The least no. of subjects were in the age

\begin{tabular}{|c|c|c|}
\hline \multirow{4}{*}{$\begin{array}{l}\text { Table 1: Definitions for } \\
\text { the MFCL Classifica- } \\
\text { tion. }\end{array}$} & K-Level 1 & $\begin{array}{l}\text { Has the ability or potential to use a prosthesis for transfers or ambulation in } \\
\text { level surfaces at a fixed cadence. Typical of the limited and unlimited household } \\
\text { ambulator. }\end{array}$ \\
\hline & K-Level 2 & $\begin{array}{l}\text { Has the ability or potential for ambulation with the ability to transverse low- } \\
\text { level environmental barriers such as curbs, stairs or or uneven surfaces. Typical } \\
\text { of the limited community ambulator. }\end{array}$ \\
\hline & K-Level 3 & $\begin{array}{l}\text { Has the ability or potential for ambulation with variable cadence. Typical of the } \\
\text { community ambulatory who has the ability to transverse most environmental } \\
\text { barriers and may have vocational, therapeutic, or exercise activity that demands } \\
\text { prosthetic use beyond simple locomotion. }\end{array}$ \\
\hline & K-Level 4 & $\begin{array}{l}\text { Has the ability or potential for prosthetic a mbulation that exceeds basic } \\
\text { ambulation skills, exhibiting high impact, stress or energy levels. Typical of the } \\
\text { prosthetic demands of the child, active adult or or an athlete. }\end{array}$ \\
\hline
\end{tabular}


group of 30-34. Also, maximum no. of subjects were in the post-operative period between 1217 months and minimum no. of subjects were found in the post-operative period between 1823 months.

To describe the functional abilities of persons who have undergone lower limb amputation, a coding system using code modifiers (K0, K1, K2, $\mathrm{K} 3, \mathrm{~K} 4)$ is used as a 5-level functional classification system (MFCL). The AMP helps in classifying the patients according to these levels. (table1) [16].

When this study was done, the patients were classified according to the MFCL system and it was found that, maximum number of subjects were in the $\mathrm{K} 1$ level of the AMP and minimum subjects were in the $\mathrm{K} 3$ level of AMP.

Amputation and anxiety: Anxiety is a normal human reaction. In moderation, it prepares the body by stimulating an adaptive response to a stressful event. However in excess it can destabilize an individual. Traumatic amputation can result in physical, psychological and socio-economic. Many studies on the psychological impact of amputation have been carried out.

Z.M. Hawamdeh, Y.S.Othman and A.I. Ibrahim (2008) conducted a study on the assessment of anxiety and depression after lower limb amputation in Jordanian patients and found that the prevalence of anxiety and depressive symptoms were $37 \%$ and $20 \%$ respectively and it was associated with female gender, lack of social support, unemployment, traumatic amputation, shorter time since amputation and amputation below the knee [18].

A study conducted by Horgan and Machlachlan (2004) concluded that although anxiety and depression appear to be relatively high upto 2 years post amputation, they decline thereafter to levels comparable to those in the general population [19]. For this reason we have included patients who have a post-operative period upto 2 years.

Mckechnie PS and John A (2002) conducted a systematic review to determine the association of depression and anxiety in traumatic amputees and found that the levels of depression and anxiety are significantly greater than in the general population [20].
V.J. Johnson, S. Kondziela and F. Gottschalk (1995) conducted a study to compare pre and postamputation mobility and the influence of age and associated medical problems and found that patients with more medical problems were poor ambulators and the cause of amputation per se did not influence mobility scores [21].

Quality of life in Amputees: Katharina Demet and Noel Martinet (2003) conducted a study on the health related quality of life and related factors in people with upper and lower limb amputation and found that HRQL was mostly impaired in the categories of physical disability, pain and energy level. Controlling for sex and age, young age at the time of amputation, traumatic origin and upper limb amputation were independently associated with better HRQL. It was concluded that HRQL is largely related to factors which are inherent to the patient and the amputation [22].

Samuli I. Saarni, Harri Sintonen and Sami Pirkola (2007) conducted a study on the HRQoL decrement and loss of quality adjusted life years associated with pure and comorbid forms of depressive and anxiety disorders and found out that chronic anxiety disorders are associated with poorer HRQoL [14].

Functional Mobility and anxiety: A study done by K.M. Mehta et al (2007) on Anxiety Symptoms and Decline in Physical Function over 5 Years in the Health, Aging and Body Composition showed that, anxiety symptoms were associated with greater hazard of self-reported mobility limitation, including difficulty walking and stair climbing [23]. Studies on the association between anxiety and functional mobility are limited. However, a decline in functional mobility can be because anxiety affects confidence and self-efficacy without resulting in any meaningful decrement in ability to perform functional tasks [24].

However, a previous study done by Singh R. et al in 2009 on depression and anxiety symptoms after lower limb amputation showed that anxiety may be present in the initial few days after amputation, but there is a drop in the levels of anxiety during the hospital stay which may rise again after discharge when the individual gets back to his daily life. This elevated level can 
persist up to 17 years. It was suggested that some of the confidence that patients were gaining during their inpatient stay may in fact be a false reassurance gained in the relative security of a hospital setting. Though they are trained for activities of daily living, it is always reassuring to know that the doctors and therapists are around them for support. Also it was suggested that younger population suffered from anxiety more than the elderly as they had lower expectations and demands of recovery right from the beginning [25].

As we can understand from the previous studies done on the prevalence of anxiety symptoms in patients with amputation and Health related quality of life in amputees, anxiety is prevalent more in male patients with below knee amputation compared to the female gender and in other types of amputations. Also, from the present study we have found that the functional mobility of an amputee is reduced due to the presence of anxiety. Thus, it is an important factor that must be considered during the rehabilitation of an amputee. Using a holistic approach including counselling for anxiety in the rehabilitation of an amputee can yield better and faster outcomes. Also, we have to take into consideration recreational training and training for activities of daily living during both in-patient and out-patient rehabilitation. It is important to have a team of individuals including counsellors and family to help the patient adjust to his new life. As we have seen from previous studies that there can be a rise of anxiety after discharge, regular psychiatric evaluations and counselling will help the patient to participate in the society.

This study is limited to only traumatic below knee amputees not using a prosthesis. Depressive symptoms were not included in this study. Further studies should focus on the functional mobility in amputees using a prosthesis, depressive symptoms in amputees and effect of counselling on the functional mobility of an amputee.

\section{CONCLUSION}

This study was done to determine the co-relation between anxiety and functional mobility in traumatic below knee amputee patients. It was concluded that there exists a co-relation between the two factors. Higher the anxiety, lower is the functional mobility and vice versa.

\section{ABBREVIATIONS}

NSSI - National Sample Survey Of India

HRQoL - Health related quality of life

AMP - Amputee mobility predictor

AMPnoPRO - Amputee Mobility predictor without prosthesis

AMPPRO - amputee mobility predictor with prosthesis

HADS - Hospital anxiety and depression scale

HADS -A - Hospital anxiety and depression scale for anxiety

HADS- D - Hospital anxiety and depression scale for depression

Funding: This research received no specific grant from any funding agency in the public, commercial or notfor-profit sectors.

\section{Conflicts of interest: None}

\section{REFERENCES}

[1]. J. Maheshwari. From Amputations, Prosthetics and Orthotics. In Essential orthopedics. $4^{\text {th }}$ Edition. Jaypee Brothers Medical Publishers (P) Ltd; 2011:318-322

[2]. Narional Sample Survey Organization, Report on the Survey of Disabled Persons, 58th Round, July-December 2002, No. 485, Department of Statistics, New Delhi, 2003.

[3]. Ghosh Das P, Lahiri S, Prevalence and aetiology of amputation in Kolkata, India: A retrospective analysis,Hong Kong Physiotherapy Journal 2013;31(1):36-40.

[4]. Seymour R. Prosthetics and orthotics: lower limb and spinal. Philadelphia: Lippincott Williams \& Wilkins; 2002.

[5]. Ziegler -Graham K, MacKenzie EJ, Ephraim PL, Travison TG, Brookmeyer R. Estimating the prevalence of limb loss in the United States: 2005 to 2050. Arch Phys Med Rehabil 2008;89(3):422-9.

[6]. Demet K, Martinet N, Guillemin F, Paysant J, Andre J$M$. Health related quality of life and related factors in 539 persons with amputation of upper and lower limb. Disabil Rehabil 2003;25(9):480-6

[7]. "Disabilities". World Health Organization. Retrieved 11 August 2012

[8]. Üstün TB, Chatterji S, Bickenbach J, Kostanjsek N, Schneider M. The International Classification of Functioning, Disability and Health: a new tool for understanding disability and health. Disabil Rehabil 2003;25(11):565-71.

[9]. Geertzen JHB. Moving beyond disability. Prosthet Orthot Int 2008;32(3):276-81.

[10]. Centers for Disease Control and Prevention. Measuring healthy days: Population assessment of health-related quality of life. Centers for Disease Control and Prevention, Atlanta, Georgia 2000. 
[11]. Gandek B, Sinclair SJ, Kosinski M, Ware JE Jr. Psychometric evaluation of the SF-36 health survey in Medicare managed care. Health Care Financ Rev 2004;25(4):5-25.

[12]. McHorney CA. Health status assessment methods for adults: past accomplishments and future directions. Annual Rev Public Health 1999; 20:30935.

[13]. Selim AJ, Rogers W, Fleishman JA, Qian SX, Fincke BG, Rothendler JA, Kazis LE. Updated U.S. population standard for the Veterans RAND 12-item Health Survey (VR-12). Qual Life Res. 2009;18(1):43-52.

[14]. Saarni SI, Suvisaari J, Sintonen H, Pirkola S, Koskinen S, Aromaa A, Lönnqvist J. Impact of psychiatric disorders on health-related quality of life: general population survey. $\mathrm{Br} J$ Psychiatry. 2007 Apr;190:326-32.

[15]. Seidel E, Lange C, Wsetz HH, et al. Anxiety and depression after loss of a lower limb. Orthopade 2006;35:1152, 1154-6, 1158.

[16]. Gailey RS, Roach KE, Applegate EB, Cho B, Cunniffe B, Licht S, Maguire M, Nash MS. The amputee mobility predictor: an instrument to assess determinants of the lower-limb amputee's ability to ambulate. Arch Phys Med Rehabil. 2002 May;83(5):613-27.

[17]. Bjelland I, Dahl AA, Haug TT, Neckelmann D. The validity of the Hospital Anxiety and Depression Scale. An updated literature review. J Psychosom Res. 2002 Feb;52(2):69-77.

[18]. Hawamdeh M Z, Othman YS, Ibrahim Al, Assessment of anxiety and depression after lower limb amputation in Jordanian patients, Neuropsychiatric Disease and Treatment 2008:4(3) 627-633.
[19]. Horgan O, MacLachlan M. Psychosocial adjustment to lower-limb amputation: a review. Disabil Rehabil. 2004 Jul 22-Aug 5;26(14-15):837-50.

[20]. Mckechnie PS, John A. Anxiety and depression following traumatic limb amputation: a systematic review. Injury. 2014 Dec;45(12):1859-66.

[21]. Johnson VJ, Kondziela S, Gottschalk F. Pre and postamputation mobility of trans-tibial amputees: correlation to medical problems, age and mortality. Prosthet Orthot Int. 1995 Dec;19(3):159-64.

[22]. Demet K, Martinet N, Guillemin F, Paysant J, André JM. Health related quality of life and related factors in 539 persons with amputation of upper and lower limb. Disabil Rehabil. 2003 May 6;25(9):4806.

[23]. Mehta KM, Yaffe K, Brenes GA, Newman AB, Shorr RI, Simonsick EM, Ayonayon HN, Rubin SM, Covinsky $\mathrm{KE}$. Anxiety symptoms and decline in physical function over 5 years in the health, aging and body composition study. J Am Geriatr Soc. 2007 Feb;55(2):26570.

[24]. Kivinen P, Sulkava R, Halonen P, et al. Self-reported and performance-based functional status and associated factors among elderly men: The Finnish cohorts of the Seven Countries Study. J Clin Epidemiol 1998;51:1243-1252.

[25]. Singh R, Ripley D, Pentland B, et al. Depression and anxiety symptoms after lower limb amputation: the rise and fall. Clinical Rehabilitation. 2009; 23(3): 281-286. J Physiother Res 2021;9(5):4013-4018. DOI: 10.16965/ijpr.2021.176 